\title{
Impacts of Digital Marketing on the Pharmacies Community in Saudi Arabia and Determining the Future Model of the Industry: A Cross-Sectional Questionnaire-based Study
}

\author{
Mansour Alyahya ${ }^{1, *}$, Sneha Dhruvakumar ${ }^{2}$, Shekar Hosahalli Siddegowda ${ }^{3}$, Nagaraja Sreeharsha ${ }^{4,5, *}$ \\ 1'Department of Management, College of Business, King Faisal University, Al-Ahsa, SAUDI ARABIA. \\ ${ }^{2}$ Kashipathi Education Trust, Off Sarjapura Road, Bangalore, Karnataka, INDIA. \\ ${ }^{3}$ Department of Pharmacy Practice, Visveswarapura Institute of Pharmaceutical Sciences, Kempegowda Hospital and Research center, \\ Bangalore, Karnataka, INDIA. \\ ${ }^{4}$ Department of Pharmaceutical Sciences, College of Clinical Pharmacy, King Faisal University, Al-Ahsa, SAUDI ARABIA. \\ ${ }^{5}$ Department of Pharmaceutics, Vidya Siri College of Pharmacy, Off Sarjapura Road, Bangalore, Karnataka, INDIA.
}

\begin{abstract}
Background: Pharmaceutical and telemedicine industries are now finding ways in the Kingdom of Saudi Arabia by adopting innovative and successful business models along with groundbreaking strategies using digital online platforms particularly after the COVID-19 pandemic. Methods: The present study analyzes the impacts and frequencies of digital marketing technology usage among pharmacies and customers. A crosssection study was carried out using a non-repeated random sampling technique and a standardized questionnaire survey was conducted employing online telephone interviews. Binomial, Chi-square, multinomial logistic regression and the multivariate statistics were applied on data sets to determine the comparison and relationship between variables and their categories. Results: These study findings revealed that customers used the web services tool of pharmaceutical companies significantly $(p<0.05)$ more than other digital marketing or social media platforms. Approximately, 36 pharmacies agreed out of 51 to the fact that webinars are effective, efficient and resourceful for online engagement with all shareholders regarding the product. Conclusion: Most respondents recognized that social media chats are to be more operative and ferocious in terms of marketing communications.
\end{abstract}

Key words: Digital Marketing, Pharmacy, Pandemic, Digitalization, Social Media.

\section{INTRODUCTION}

In the modern world, businesses are growing and getting affected due to the ever-changing behavior of the customers and the implementation of different kinds of digital market strategies. Pharmacies are also a part of this spectrum and likewise, they have faced constant challenges and transformed their business models to cope up with the changing environment. As the world is moving towards technological advancement, e-pharmacies is becoming a new trend around the globe especially in the first world countries where people are more digitally aware. The digital world offers various advantages such as the sale is less time-consuming, provides ease of interaction with the customer, financially viable and cost-efficient. After COVID-19 pandemic 2020 many businesses adapted and transformed to offer services digitally to avoid physical contact ensuring the safety of the employees and the customers. Chiplunkar et al. ${ }^{1}$ reported that this disruption is in line with the trend in the movement of doctors and patients to the internet, for satisfying their information
Submission Date: 18-08-2020; Revision Date: 26-10-2020; Accepted Date: 22-11-2020

DOI: 10.5530/ijper.54.4.174 Correspondence:

Dr. Mansour Alyahya Department of Management, College of Business, King Faisal University, Al-Ahsa-31982, SAUDI ARABIA.

Phone: +966 503912221 E-mail: malyahya@kfu. edu.sa

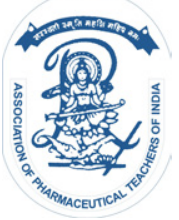

www.ijper.org 
needs through web platforms, medical websites, e-detailing, e-CMEs, webinars, video conferencing, telemedicine and the like. During the Pandemic another stakeholder in this process has emerged in the form of Government, provided SOP's to all pharmacies and made effective progress. Similarly, following the steps, the Governments need to collaborate with pharmacies to provide them with nationwide recognize criteria and standards so that illegal activities be shut down thereby, increasing the trust of the people. This step can help more people to trust digital mediums and use it frequently. Hence, there is a need to do 'location-specific research' to get a wider picture of the transformation. Alkhenizan ${ }^{2}$ reported that the pharmaceutical industry in the Arab region is growing at a steady pace. More than 25 million people combatted a global pandemic called Covid-19 caused by the coronavirus. Amid these affairs, many countries, especially the ones with a good public healthcare system where healthcare is the top priority of the government, increased their annual fiscal budget share dedicated to providing healthcare services. One such country is the Kingdom of Saudi Arabia. The Saudi Arabian Ministry of Health reported that for the fiscal year 1440/1441H (2019-2020) budget totaling SR $75,403,859,000$ (equivalent to USD 20,105,164,677), allocated to the Ministry of Health $(\mathrm{MOH})$ has been approved by an increase of SR 11,106,595,000 (equivalent to USD 2,961,385,855), compared to the budget of the last fiscal year 1439/1440H (2018$2019)$, at a rate of $6.82 \%$. An increased health budget coupled with a global pandemic brings about the need to increase in digital aspects of healthcare, including but not limited to digital marketing. The growing healthcare market gave rise to the study of Pharmacoeconomics in the Kingdom of Saudi Arabia. ${ }^{3}$ Radu et al. ${ }^{4}$ revealed that the internet, e-mail, and social media are not only cheaper methods than direct marketing, but they also create the opportunity to market a service to virtual costumers, breaking the barrier of distance and making consumers aware of the service being offered at any time and any place. ${ }^{5}$ It is believed that digital marketing is overall a smart proposition during the given era towards the target augment. ${ }^{6}$ Many consumer products and services, especially pharmaceuticals, are opting to reach their target marketing through digital marketing. ${ }^{7}$ Traditional digital marketing techniques such as emails, newsletters, magazines, newspapers and subsequent reminders are not so popular nowadays. The reason is primarily due to fluctuations in the digital trends and the marketing industry in general that have created a much larger competition. Many marketing emails land into the consumers' spam or junk folder or are deleted unopened and unread, from the email inbox. ${ }^{8}$

Currently, we are living in a digital age. It has become difficult for the business to keep attracting customers without a digital presence. Consumers search online when looking for products, services and solutions. Today end consumers are ahead of the producers in the use of digital technologies and they are not passive consumers of information, which is obtained through the traditional transmission channels. ${ }^{9}$ Parekh et al. (2016) revealed that digital marketing in any sector is a more cost-effective and less time-consuming method to communicate with customers compared to traditional marketing. It allows pharmaceutical marketers to use data to create more strategic engagement with prescribers and physicians. The most used tool for digital marketing is social media. It is quite a cost-effective tool and is used to directly communicate the marketing message to the relative target audience. ${ }^{10,11}$ Sarringhaus (2011) described social media as an untapped innovative resource in healthcare. One study found that webinars carried a much more significant influence on positive transformations in clinical practices compared with other digital media. ${ }^{12}$ The effectiveness of webinars for inducing change might be due to the fixated nature of the discussion on a specific topic, the interactive question and answer sessions and the one-hour time commitment. Doctors and Physicians who find the time to participate in an online webinar session are usually self-motivated to engage with that medical topic. The reasons for the success of webinars in prompting change is currently being explored further. ${ }^{13}$ Digital engagement has become a supportive alternative to face-to-face engagement with target market audiences. ${ }^{1}$ The factor of digitalization has also brought a new sense of competition within the pharmaceutical industry. Every pharmacy is trying to create a different system and bringing in new elements to distinguish itself in the market to earn the trust of the customers. The business models of pharmaceutical companies vary; some of them are working to become increase their range and become a national level brand and others are striving to engage more locals. ${ }^{14}$

By considering the importance of digital media in the field of the pharmaceutical industry, the objective of the present research study is multilayered; it includes the impacts of digital marketing on the pharmacies, the reaction of the customers and getting to know whether the use of digital marketing holds the potential to replace the typical setup of the pharmacies. This study will also be a milestone in generating recommendations to improve the digital business structure of the pharmacies. Research involves the contemporary landscape of the 
digital market, OTC (over the counter) drug/prescribed drugs and the opportunities available to pharmacists in the form of digital marketing. It also encompasses the elements that can be redefined and reshaped the entire future of pharmaceutical industries.

\section{MATERIALS AND METHODS}

\section{Study Design, Sampling, and Questionnaire Data}

A cross-sectional study based on a questionnaire was designed and carried out in the pharmacy communities comprising of pharmacy companies and customers using the non-repeated random sampling technique. Opting for a questionnaire is ideal to understand different dynamics and the factors involved with the impacts of digital marketing on the pharmacies and to produce a result that is helpful to pharmaceutical business models. The questionnaire consisted of two sets with 12 questions each. One set of questions named, 'Pharmacy Set', dispatched via email to major pharmacies in Saudi Arabia. The other set named 'General Set', designed for the general public and it was shared using social media platforms i.e. WhatsApp and Facebook. The advantages of conducting online surveys include access to individuals in distant locations, the ability to reach many participants thus increasing sample size and the convenience of having data collection, which reduces researcher time and effort. ${ }^{15}$ The answers recorded in the questionnaire and categorical variables were processed via numerical coding in IBM SPSS version 26 and presented in the form of percentages and frequencies.

In the Pharmacy set of the questionnaire, groups were formed based on locality: whether a pharmacy is set up in the regional area or the city, In the General Set, groups were formed on basis of gender and occupation status. In the pharmacy setting, questions were constructed on basis of the following terms; Digital spectrum, online platforms for services and advertisement, digital channels for communication with stakeholders, impacts on product sale by digital marketing, COVID-19 pandemic effects on business, demand of e-pharmacies, hiring technical employees for digital marketing and online customer dealing and Government SOPs for proper digitization of pharmacies. In the general data set, we recorded customers' responses by constructing questions based on their online purchasing frequency affected by the type of medicine, kind of online platform, quality of the product, delivery time and charges, customer service, and advertisement influence.

\section{Human Ethics}

The people who participated in this research work were properly informed and the consent was taken from them. The team made sure that there was no dangerous or ambiguous factor involved in the entire study. The participants were even allowed to withdraw their responses at any if they wanted to. The research team made sure that there was no involvement in deceptive practices.

\section{Statistical Analysis}

The data obtained from the questionnaire survey were coded and analyzed using 26 Version of SPSS (IBM, Armonk NY, USA). To reveal the patterns, trends, and probabilities, the descriptive statistics were applied against raw data of both data sets (General and Pharmacy). One-sample binomial, chi-square, multinomial logistic regression and multivariate analysis were performed to determine the comparisons, relationship between variables, and their categories. Cross tabulation and descriptive statistics were also performed to determine the quantitative relationships between digital online platform selection and type of medicine against the purchasing frequency of customers. Data was visualized and presented in the graphical form of frequencies and percentile using SPSS statistical tools.

\section{RESULTS \\ Regional classification of pharmacies}

Out of the 55 pharmacies that were taken into this research study, $35(63.6 \%)$ pharmacies belonged to a metropolitan vicinity while $20(36.4 \%)$ pharmacies were in the regional area. An exact one-sample binomial test with exact Clopper-Pearson showed a significant difference $(\phi=0.045)$ between metropolitan and regional vicinity at 95\% CI of 0.504 to 0.744 (Figure 1). The output of one-sample binomial test rejected the hypothesis based on p-value that is revealing that higher percentage/number of pharmacies found in metropolitan than regional area (Figure 1a).

The inclusion of the locality factor facilitated in understanding a clear-cut pattern that technology, awareness and finances play a vital role while leaning towards the concept of digital marketing. The data indicated that the pharmacies in the region are adapting to the change and absorbing new trends and continuously changing their business model, especially after the Covid-19 Pandemic. When it comes to the business approach, pharmacies are taking to increase their digital clout, a surprising trend can be witnessed as most of 
the pharmacies around 30 included in this survey are dealing in both OTC and Prescription Medicine. They have devised a legal mechanism and a license that allows them to verify a prescription digitally by contacting the source. While just 6 pharmacies are specialized and only deals in Prescription Med and they all use the abovementioned process.

\section{Understanding the portfolio, spectrum of services offered by the pharmacies and digitalization}

The rest 18 of the pharmacies in this study are dealing with just OTC drugs because it comes with less legal hurdles and it provides them the adequate space to improve their services by removing the ambiguity in the entire digital chain. A significant difference $(\phi<0.05)$ was observed in all three categorical approaches in the digital spectrum for medicine type adopted by pharmacy companies (Figure 2a).

The third question was asked about the kind of online platform pharmacies are using to offer their services, 54 responses recorded the following data: The trend was quite interesting as it revealed that pharmacies have seriously worked on their digital structure and more than half, $28(52 \%)$ pharmacies have designed their websites with a digital store and $14(26 \%)$ of the pharmacies have developed a digital application to reach out to their customers. Besides that, $12(22 \%)$ pharmacies were using social media apps to engage their customers, the limitation shows that they are more personal and want to be more private. One sample chi-square results rejected the null hypothesis and concluded that web services were one the significantly $\left(X^{2}(5)=55.14, p=\right.$ 0.000 ) associated and highly adopted online platform followed by the digital app as the best source in terms
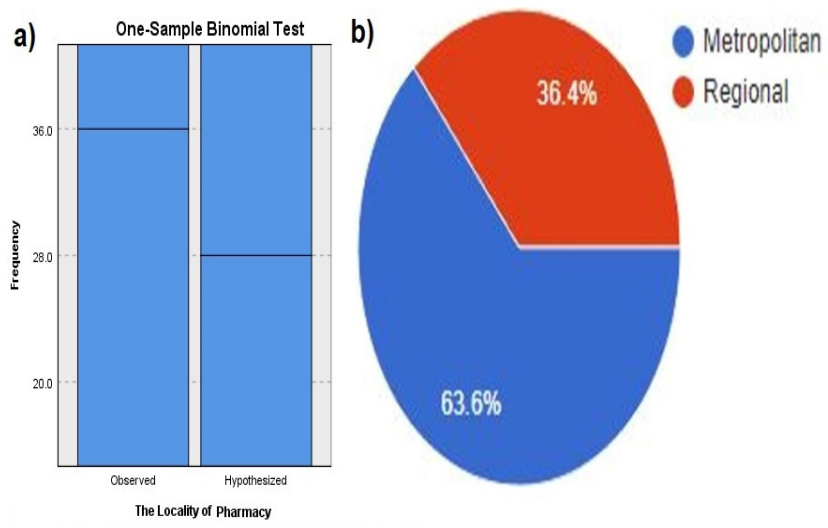

Figure 1: The first question about the locality of pharmacy showing the percentage of metropolitan and regional pharmacies. a) One sample binomial test indicating the observed and hypothesized frequencies with significant difference $(p=$ 0.045), b) a pie chart showing the percentage of metropolitan and regional locations of pharmacies. to provide services to their customers. However, a very low proportion of social media apps such as WhatsApp $(11 \%)$, Facebook (5.5\%) and Instagram (5.5\%) are using by pharma companies regarding the availability of their services (Figure 3).

\section{Understanding the prefererential digital media utilization}

This study also included a question, where the pharmacies were asked about the kind of digital medium, they were using to advertise their services. In response, 54 pharmacies were given a choice from 5 platforms (YouTube, WhatsApp, Snapchat, Instagram, and Facebook) and they could choose multiple options. The recorded data showed more than half 29 (52.3\%) pharmacies advertise their services on Instagram, followed by 28(50.9\%) YouTube, 27(49.1\%) Facebook, and $(47.3 \%)$ WhatsApp. Whereas, Snapchat was the least preferable $17(30.9 \%)$ online social media platform by pharmacies to advertise their service. among all online platforms and their combinations (Figure 4). The data indicates that pharmacies are trying to update their conventional ways and now transforming themselves to open new channels for the advertisement of their services. They have carefully designed and build up audiences on their Facebook pages, Instagram accounts and even new YouTube channels to raise awareness regarding healthcare issues. WhatsApp, YouTube, and Facebook online were found significantly $(p=0.032)$ more by pharmacies to advertise their service.

There is also a new to understand the channel of communication between customers and the service providers and to understand this phenomenon, the study included a question that specifically asked the pharmacies about the channel they use to develop communication with customers and the data illustrated

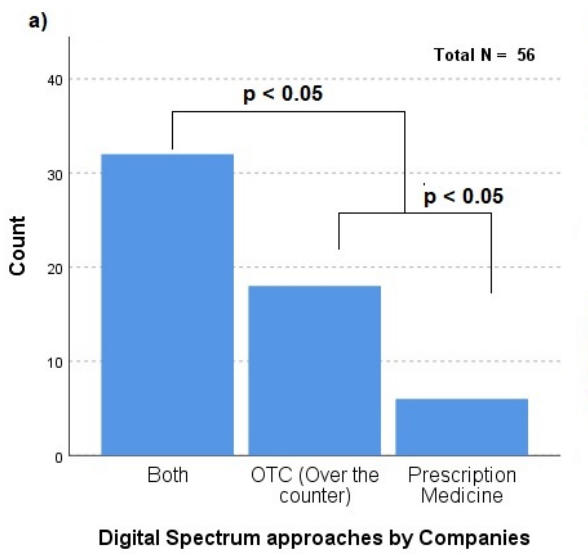

b) - OTC (Over the counter) - Prescription Medicine Both

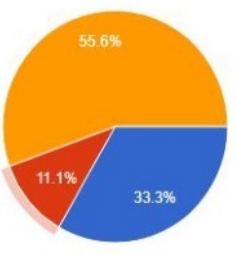

Figure 2: Digital spectrum approaches used by pharmacy companies indicated by showing a) significant difference among approaches and b) percentages. 
the trend in Figure 5. WhatsApp leads the way with 22 $(40 \%)$ pharmacies acknowledging the use of this channel of communication because it is secure and effective and provides an instant response with a significant difference $(p=0.000)$ than Instagram $(6 \%)$ and messenger $(16 \%)$. Web Chat comes second with $21(38 \%)$ respondents admitting the use of this medium because it is more professional and helps in the development of an efficient feedback system.

Since it's the beginning of a digital transformation of pharmacies so the study also included a question relating to a single platform that is ideal to engage all the stakeholders involved in the chain. Among 54 responses,

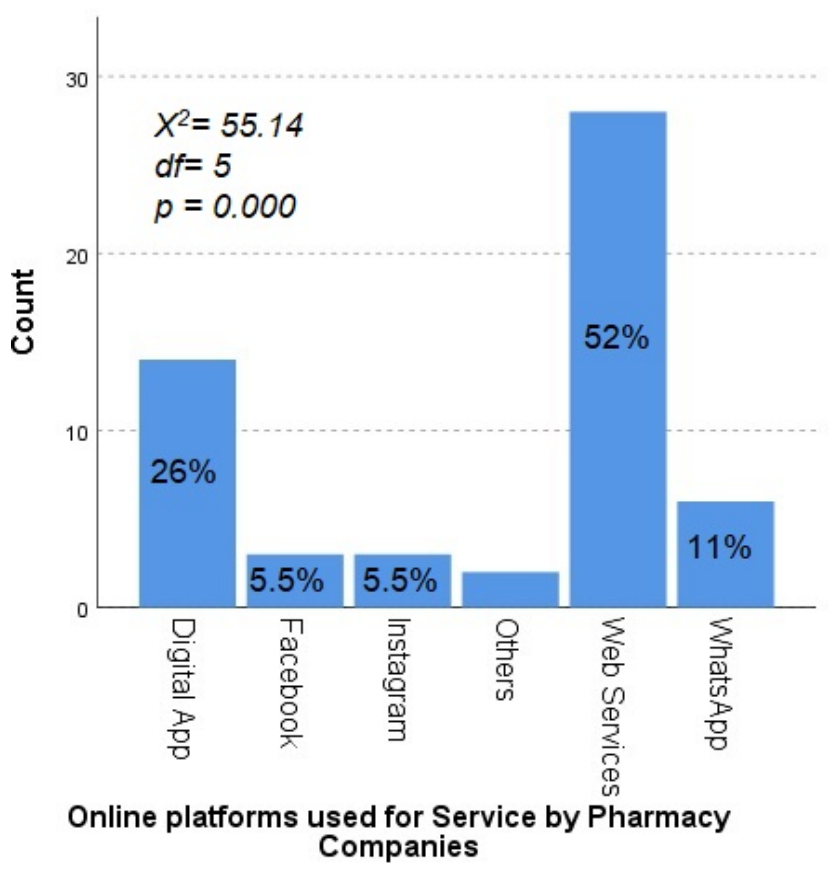

Figure 3: Frequency and percentages of online platforms used by pharmacy companies in providing the services with significant differences $(p<0.05)$.

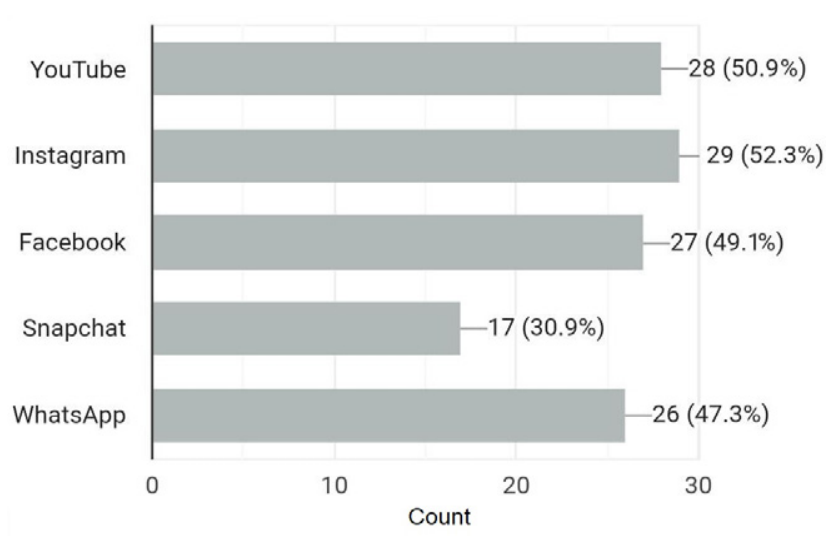

Figure 4: Frequency of exclusive and multiple online platforms used by pharmacy companies for the advertisement of their products.
$66.7 \%$ of pharmacies prefer to use the Webinar with significant difference $(p=0.000)$ than YouTube $(18.5 \%)$ and Seminars (14.8\%) to engage with their stakeholders (Figure 5).

Most of the pharmacies about 36 agreed to the fact that webinars are effective, efficient and resourceful. Conducting Webinars is the most effective way to involve all the stakeholders in the digital transformation of pharmacies (Figure 6). It contains manifold advantages: proper use of webinars can ease the transformation, provide a more in-depth analysis of the system, points

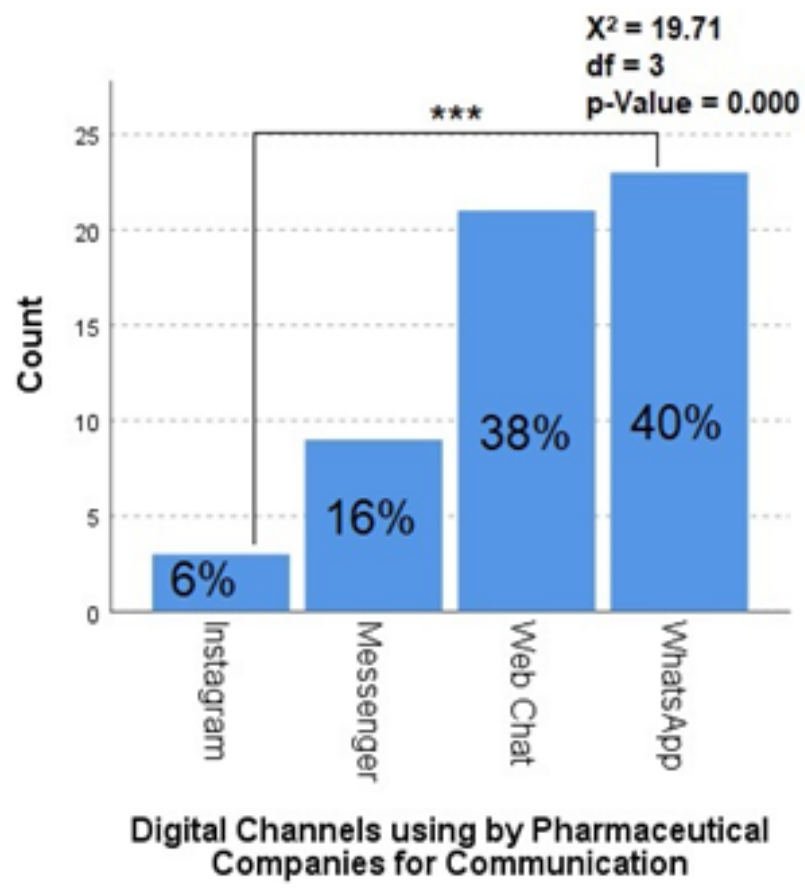

Figure 5: Frequency and the percentage of digital channels used by pharmacy companies for communication with significant differences.
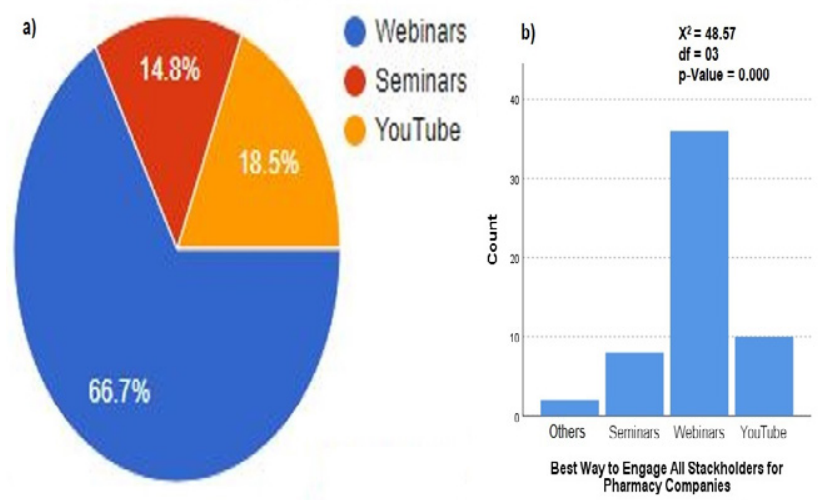

Figure 6: a) Percentage and b) frequency response with a significant difference by pharmacy companies between digital online channels, to figure out the best way engagement source with all stakeholders. 
out flaws of the system and linearize the chain of communication.

The next question was designed to understand the influence of digital marketing on the business aspect of the pharmacies. 53 responses recorded and unsurprisingly data clearly showed that digital marketing affected every pharmacy included in this research study. Going from minimum (1 level) to maximum (10 levels), level 7 (above average) showed the maximum frequency $16(30.2 \%)$ of about 16 pharmacies ticked at this level (Figure 7). This fact showed the importance of digital marketing and how much it influences the business models of the pharmacies.

Coming back to the physical nature of digital marketing, pharmacies were asked a simple question about their sales. A significant difference $(p<0.05)$ was observed in responses. Out of 51 responses, 42 pharmacies said that their sales went up due to the inclusion of digital marketing while only 9 disagreed and said their sale was not affected after the inclusion of digital marketing.

To understand the relationship between the use of digital mediums and the financial hit that most businesses across the globe took during the COVID-19 pandemic a question was asked. Similarly, a significant difference $(p<0.05)$ was observed in which out of 52 responses, 45 pharmacies acknowledged the fact that digital marketing helped their business during the pandemic. It helped to retain their sales and allowed them space to breathe and adapt to the new conditions.

Since digital marketing holds the capability to increase the range of the business, a question was asked from the pharmacies whether it increased their range and brought order from other parts of cities or didn't. we observed a nonsignificant difference $(p>0.05)$ in which out of 53 responses, 64 percent that is about 34 pharmacies admitted that digital marketing helped them

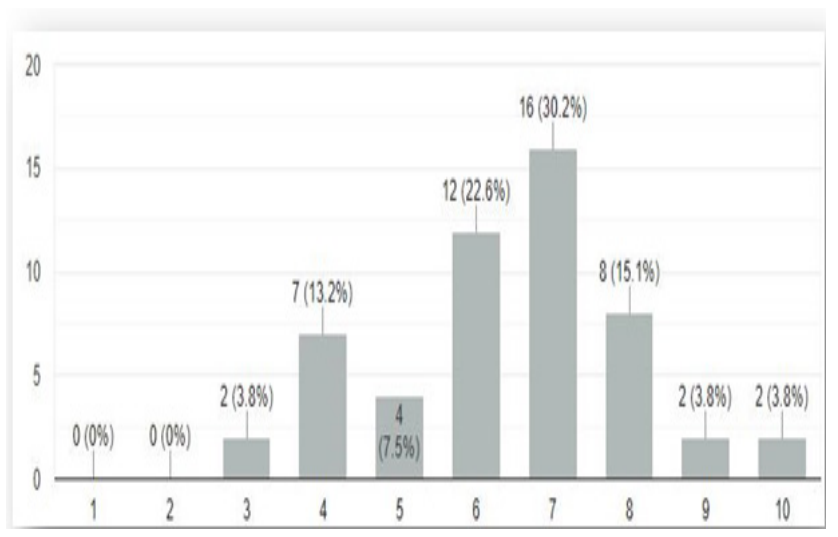

Figure 7: The influence of digital online marketing scaled from minimum to maximum (1-10) by percentages and counts. to increase their business range and allowed them to reach more customers. Whereas 30 of the respondents were not sure about this and only 5 said that there was no increase in their range.

The pharmacies were asked about their view regarding the demand for E-Pharmacies, out of the 53 responses, 34 said that the demand for E-Pharmacies has increased over time while 16 pharmacies were not sure about this and only 6 disagreed with significant difference $(p<0.05)$ and said that this unconventional way hasn't found its audience yet.

There are several dimensions to Digital Marketing that are causing a revolution in the pharmaceutical industry and one of that is the staff and its management. To have an idea about the size of this change a question was asked relating to the hiring policies of the pharmacies. Out of the 52 responses, 28 disclosed that they have changed their hiring policies. They have let go of the staff that was unnecessary after the indirection of the digital medium and now they prefer quality over quantity model. They have linearized the hierarchy to be more direct and efficient. About 34 percent, 16 pharmacies were not sure or didn't want to disclose this information while 12 percent about 6 pharmacies said they have not brought any change in their hiring mechanism with significant difference $(p>0.05)$.

To strategize, implement and take full advantage of Digital Transformation it requires technical staff. A question was asked under the given premises, out of the 55 responses, 33 pharmacies admitted the fact that the process of digital transformation requires technical handling and without technical management, it becomes difficult to satisfy customer needs so they have changed their style of management and hiring especially the HR department. Now the focus is to maximize efficiency without putting an extra burden. We observed an insignificant difference between responses in which 30 percent of about 16 pharmacies were not sure about the phenomenon while 11 percent disagree.

Without a proper feedback system, any operation is bound to collapse the same case can happen with digital marketing. A similar question was asked and out of 53 responses, 31 pharmacies told that they have devised a proper feedback system where every action is processed and held accountable if needed and this helped them to reach their full potential. If the company does not possess a feedback system, its losses communication with a stakeholder, and that increases the gap and puts a different kind of hurdles in every department of the company. 32 percent that means 17 of the pharmacies were not sure that they have a proper feedback system 
while only 5 pharmacies said they don't have any form of the feedback system.

Coming back to the physical nature of digital marketing, another simple question was asked from the pharmacies relating to their finances under digital marketing. We recorded 54 responses with a significant difference $(p<0.05)$ in categorical responses. Most of the participants in this research study admitted that their finances have gone up due to the introduction of digital marketing in their business model. 55 percent simply agreed with prior opinion while 11 percent strongly agreed with it and 20 percent remained neutral and gave no opinion while only 7 strongly disagreed with the notion (Figure 8).

Another categorical question was asked from pharmacies, it encompassed the inquiring relating to the SOPs by government. We observed a significant difference $(p<0.05)$ among 53 responses in which 21 pharmacies agree for government intervention for the benefit of both people and the business and supported the narrative that government should provide proper guidelines to regularize this digital transformation. As result, 21 (39\%) pharmacies strongly agreed with the prior notion about 15 (28.3) pharmacies remained neutral and didn't give any opinion while 6 pharmacies strongly disagreed and said the government should not interfere or provide any kind of SOP (Figure 9).

\section{Understanding the perspective of customers based on demographic profile}

To get a whole picture, this study also included the perspective of the customers. The settled trends help to comprehend the effects of digital marketing and the adapting nature of the market always indicates the right direction. Divided into 2 major groups: sex and

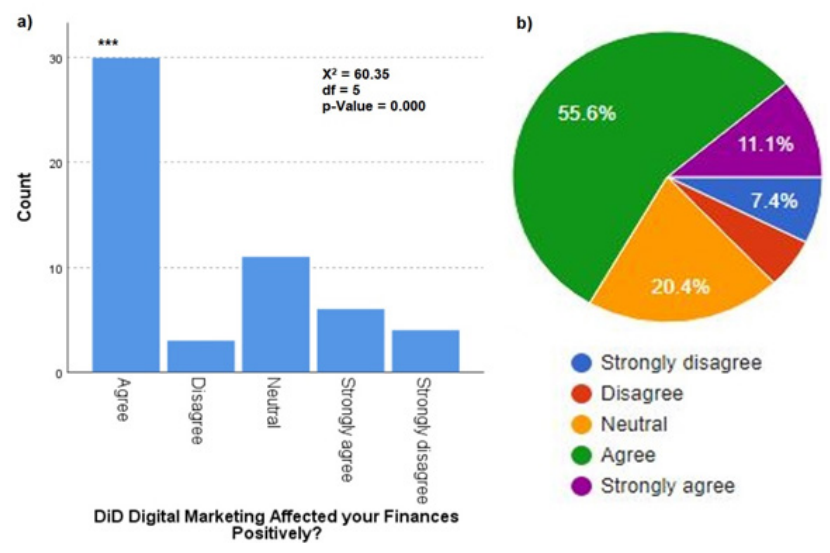

Figure 8: A categorical response against the question "Did digital marketing affected your finances positively?" by pharmacy companies in the form of a) frequency with significant difference $(p<0.05)$ and $b)$ percentages occupation. The division of the participants in the prior mentioned groups gives this research study a better dimension. One-sample binomial test showed significant difference $(p<0.05)$ indicating participants included 141(70\%) were male, 59(29\%) female and 1 percent (3) preferred not to answer (Figure 10a).

In the occupation group, one-samplethe binomial test indicated an insignificant difference $(p=0.079)$ between employed and unemployed customers. Based on occupation status 55 percent (112) people are employed, 40 percent (82) people identified themselves as unemployed and 5 percent (6) are students (Figure 11a-b). Upon asking whether the participants are already subscribers to any pharmaceutical company, we observed an insignificant difference $(p=0.123)$ with 56 percent of people (133) said no while 44 percent (90) people accepted that they are already subscribers.

In the next question, we asked about their frequency of buying medicine in a year, 202 responses were recorded and scaled from the minimum level to maximum level
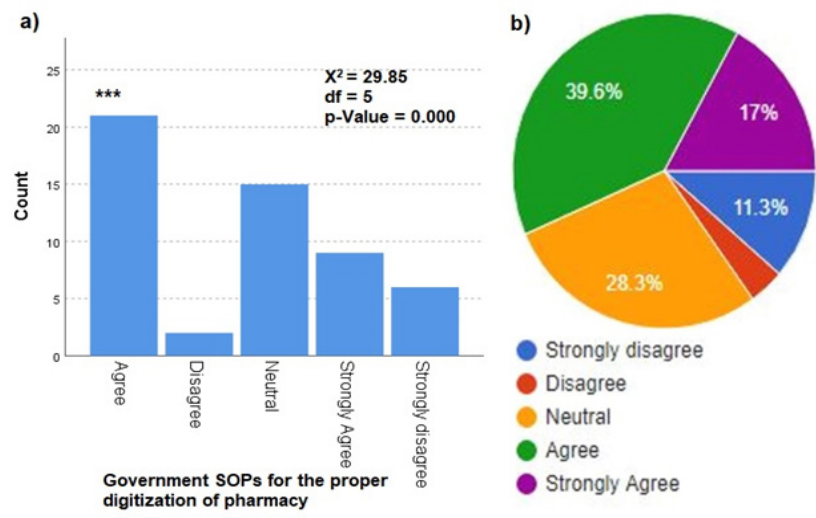

Figure 9: Another categorical response by pharmacies regarding Government SOPs for the proper digitization of the pharmaceutical industry indicated by a) frequency with significant difference $(p<0.05)$ and b) percentages.
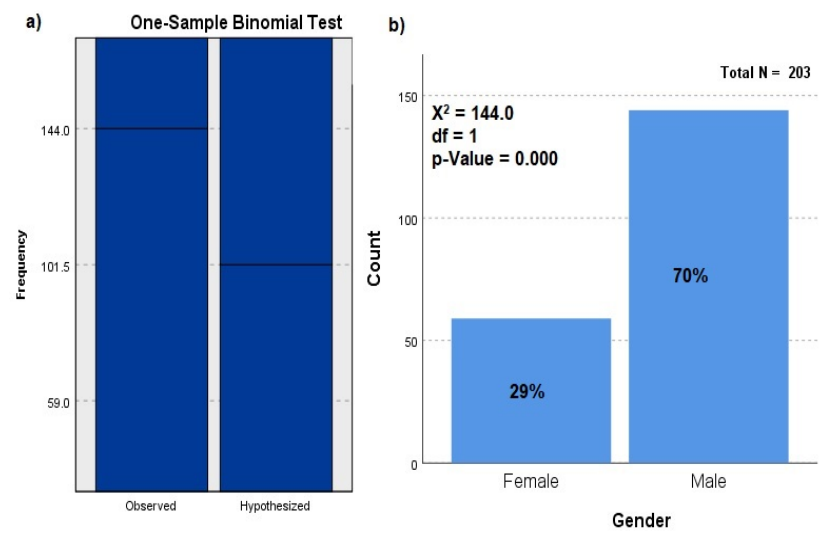

Figure 10: One-sample Binomial test indicating the a) frequency/count and $b$ ) the percentage of gender participated in this study with significant difference $(p<0.05)$. 
(1-10). From min level 1 to max level 10,104 participants opted to go from level 4 to level 6. It depicts that participants are aware of the pharmaceutical market. To determine the relationship and effect of online platform and type of medicine on the medicine buying frequency. Multinomial logistic regression results indicated that medicine buying was not insignificantly $(p>0.05)$ affected by the online platform and the type of medicine (Table 1).

Cross tabulation revealed the count of medicine buying from minimum to maximum scale against the online
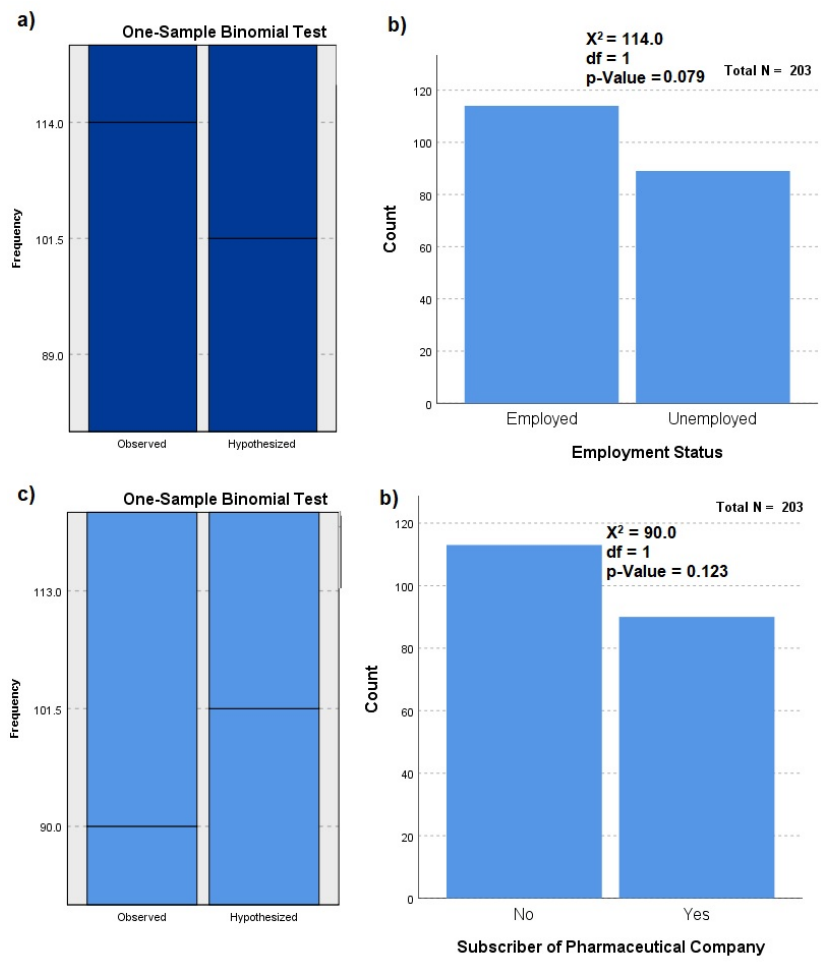

Figure 11: One sample binomial test a-c) showed the frequency of observed and hypothesized categories with the insignificant difference ( $p>0.05$ ) between b-d) employment status and subscribers.

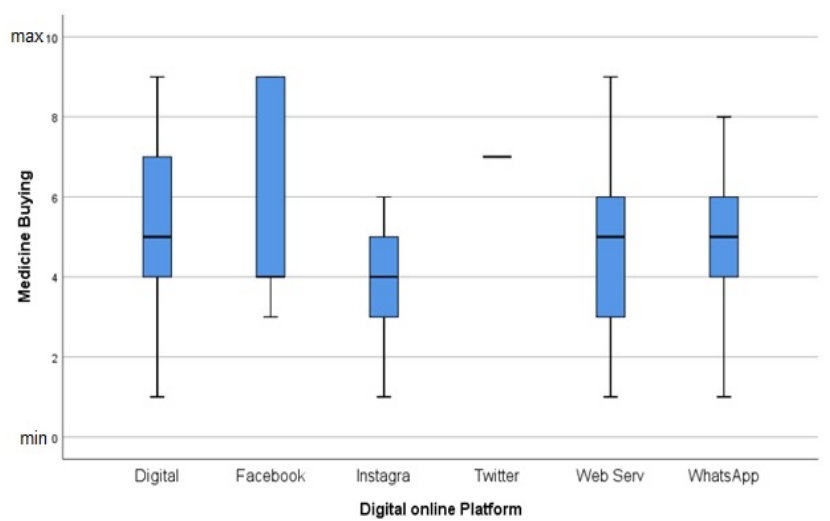

Figure 12: Cross tabulation showing the relationship of digital online platforms with medicine buying levels 1-10 (minimum to maximum). platforms (Figure 12). On an average scale (5-6) digital apps and web services were used significantly high and positively associated with medicine buying (Figure 12).

Advertisements play a key role in digital marketing; a question was asked from the participants regarding the influence of online advertisements. Out of 203 responses, 44 percent people (90) accepted that they get influenced by the advertisement they see on digital mediums, 40 percent people (77) they were not sure about themselves whether they get influenced or not and only 17 percent people (36) said that they do not get influenced by the online advertisements.

Upon asking the type of medicine they buy online, 39 percent of people (79) answered over-the-counter drugs, only 12 percent (25) answered prescription while the majority of the participants 48 percent people (97) said they buy both kinds of medicines. Coming to the core topic, when asked about the type of platform they use to buy medicines, 201 responses recorded as shown in Figure 13.

The recent introduction of E-Care programs in the pharmaceutical industry in Western Europe and the United States of America prompted a question regarding its introduction in Saudi Pharmaceutical Industry. Upon asking the people whether they would be interested in a similar program, surprisingly out of 203 responses 65.5 percent people (133) said that they would be interested in such a program while 25.5 percent people (52) showed a lack of interest and were unsure about their interest while only 9 percent people (18) said no, they won't be interested in such a program.

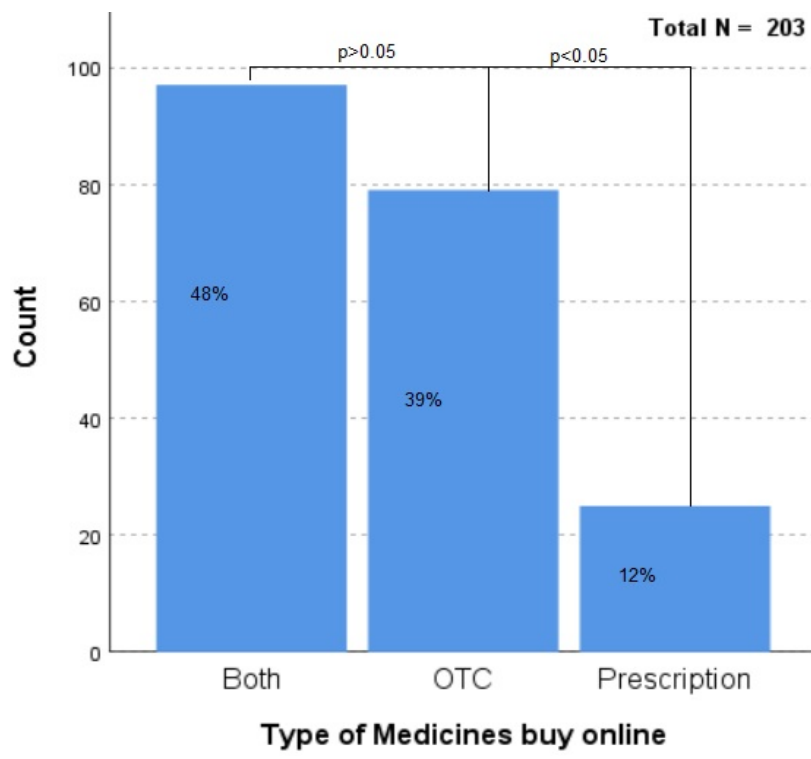

Figure 13: The type of medicine bought by the customer on different online platforms. 
Similarly, another question of a parallel nature was asked about webinars. Out of 203 responses, 59.5 percent people (121) said that they would be willing to attend webinars on E-Pharmacies, 27.5 percent people (56) said that they were unsure about attending such an event while only 13 percent people (26) said that they won't attend such a meeting.

Unsurprisingly when asked about sharing their private medical data online with a pharmacy, 74 people showed concern and said they would be hesitant doing such an activity, 48 people were also not convinced to share their data with a pharmacy online and relatively high about 79 people admitted that they will be comfortable sharing their medical data with a pharmacy to devise an E-Care Plan. When asked about the quality of the product that the participants get when they order online, the majority of the people 56 percent (113) disclosed that they get due concerns regarding the quality of the product, 23 percent people (46) showed it sometimes and the renaming 21 percent (43) said that they are never bothered by the quality of the product because of their past experiences. When asked about customer satisfaction, out of 203 responses, 43 percent people (88) said that they are currently satisfied with Customer Services provided by their respective pharmacies, 32 percent (66) were not sure while relatively a huge portion about 24 percent (49) said that they are not satisfied with the current Customer Services.

Two key factors play an important role in the success of the digital revolution: delivery time and delivery cost. Considering these factors in the research study, a couple of questions were relating to the delivery time and delivery cost (Figure 14).

From min level 1 to max level 10, most of the participants went between levels 4-6 which depicts that there is a huge room for improvement in those departments.

Multivariate analysis (MANOVA) was applied to determine the effects of online platforms used by customers for buying against medicine buy, concerns

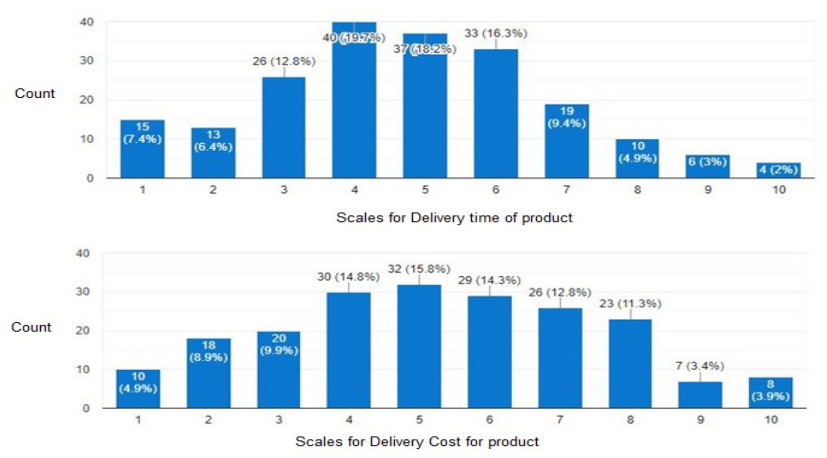

Figure 14: Percentage and counts for the scales for delivery time and delivery cost of the product. on delivery time, and charges (Table 2). The analysis revealed that online platforms did not affect the delivery time and charges of the product except the medicine buy counts.

Scamming is an unnatural part of digital marketing; it eradicates mutual trust and therefore it is necessary to know the trend in Saudi Market and surprisingly it is very low. Approximately, 85 percent of people said that they have never been scammed online purchasing medicines while 15 percent said they have been scammed one way or another, this is another issue that needs proper attention and SOP's to combat it and bring it to minimum levels.

The final question in the research study was asking people whether they would suggest other people buy medicine online or not. This is an integral question because it shows the trust of the people in the entire digital mechanism. 50 percent of people (101) nodded affirmative and said they would advise other people to use digital platforms for buying medicines, 34.5 percent of people (70) said that might advise other people to buy medicines online. These are the people that the system needs to show more attention and care and resolve their issue so that more people come into digital clout. Only 15 percent of people (32) disagreed and no they won't advise other people to use digital platforms to buy medicines online.

\section{DISCUSSION}

This cross-sectional questionnaire-based study evaluated the impacts of online digital marketing platforms on buying frequencies by the different responses of pharmacies communities (pharmacy companies and\& customers) in Saudi Arabia. We performed multiple statistical analysis and visualization to evaluate the response of pharmacy communities (pharmacy companies and customers). Response from the pharmacy companies against 17 questions was analyzed by non-parametric tests of one-sample binomial and chi-square to determine the significant association of variables with promotional online digital tools. In the response ofto our first question, a significantly high number of pharmacy companies exist in metropolitan vicinity as compared to regional surroundings. It may be explained by the fast-growing pharmacy market facilities and population in metropolitan as compared to regional areas. $\left.{ }^{[15}\right]$. In the second question, most of the Saudi pharmaceutical companies who are willing to venture further into the digital marketing sphere is using both OTC and prescription approach to developing their digital clout and there is a significant $(p<0.05)$ portion 
Table 1: Parameter estimates of multinomial logistic regression to indicating the relationship of online platform and type of medicine against the dependent variable medicine buying measured on a scale from 1-10 (minimum to maximum).

\begin{tabular}{|c|c|c|c|c|c|c|c|c|c|}
\hline \multicolumn{10}{|c|}{ Parameter Estimates } \\
\hline \multirow{2}{*}{\multicolumn{2}{|c|}{ Medicine Buying $^{a}$}} & \multirow[t]{2}{*}{ B } & \multirow[t]{2}{*}{ Std. Error } & \multirow[t]{2}{*}{ Wald } & \multirow[t]{2}{*}{ df } & \multirow[t]{2}{*}{ Sig. } & \multirow[t]{2}{*}{$\operatorname{Exp}(B)$} & \multicolumn{2}{|c|}{$\begin{array}{c}\text { 95\% Confidence Interval for } \\
\text { Exp(B) }\end{array}$} \\
\hline & & & & & & & & Lower Bound & Upper Bound \\
\hline \multirow{9}{*}{$\begin{array}{l}\text { Minimum } \\
(1-2)\end{array}$} & Intercept & 11.825 & 212.326 & .003 & 1 & .956 & & & \\
\hline & [Digital App] & -10.104 & 212.325 & .002 & 1 & .962 & 4.093E-5 & $7.601 \mathrm{E}-186$ & $2.204 \mathrm{E}+176$ \\
\hline & [Facebook] & -26.150 & 1104.789 & .001 & 1 & .981 & 4.399E-12 & .000 &.$^{b}$ \\
\hline & [Instagram] & -10.540 & 396.705 & .001 & 1 & .979 & $2.645 E-5$ & .000 &. \\
\hline & [Twitter] & -9.747 & 10996.363 & .000 & 1 & .999 & $5.846 \mathrm{E}-5$ & .000 &. \\
\hline & [Web Services] & -9.770 & 212.324 & .002 & 1 & .963 & 5.713E-5 & 1.061E-185 & $3.074 \mathrm{E}+176$ \\
\hline & [Both] & -1.982 & 1.428 & 1.928 & 1 & .165 & .138 & .008 & 2.261 \\
\hline & [OTC] & -1.027 & 1.474 & .486 & 1 & .486 & .358 & .020 & 6.431 \\
\hline & [Prescription] & $0^{c}$ & . & & 0 & . & . & . & . \\
\hline \multirow{9}{*}{$\begin{array}{c}\text { Below } \\
\text { average } \\
(3-4)\end{array}$} & Intercept & 12.662 & 212.324 & .004 & 1 & .952 & & & \\
\hline & [Digital App] & -10.691 & 212.323 & .003 & 1 & .960 & $2.276 \mathrm{E}-5$ & 4.242E-186 & $1.221 \mathrm{E}+176$ \\
\hline & [Facebook] & -11.438 & 212.323 & .003 & 1 & .957 & $1.078 \mathrm{E}-5$ & 2.010E-186 & $5.778 \mathrm{E}+175$ \\
\hline & [Instagram] & .327 & 323.943 & .000 & 1 & .999 & 1.386 & 2.517E-276 & 7.637E+275 \\
\hline & [Twitter] & -9.896 & 8334.294 & .000 & 1 & .999 & $5.036 \mathrm{E}-5$ & .000 &.${ }^{b}$ \\
\hline & [Web Services] & -9.920 & 212.323 & .002 & 1 & .963 & 4.919E-5 & 9.174E-186 & 2.637E+176 \\
\hline & [Both] & -1.513 & 1.234 & 1.503 & 1 & .220 & .220 & .020 & 2.474 \\
\hline & [OTC] & -.728 & 1.277 & .325 & 1 & .568 & .483 & .040 & 5.897 \\
\hline & [Prescription] & $0^{c}$ & . & . & 0 & . & . & . & . \\
\hline \multirow{9}{*}{$\begin{array}{l}\text { Average } \\
\quad(5-6)\end{array}$} & Intercept & 11.266 & 212.326 & .003 & 1 & .958 & & & \\
\hline & [Digital App] & -11.132 & 212.322 & .003 & 1 & .958 & $1.464 \mathrm{E}-5$ & 2.732E-186 & $7.850 \mathrm{E}+175$ \\
\hline & [Facebook] & -12.902 & 212.323 & .004 & 1 & .952 & $2.492 \mathrm{E}-6$ & 4.644E-187 & 1.337E+175 \\
\hline & [Instagram] & -.171 & 323.943 & .000 & 1 & 1.000 & .842 & 1.530E-276 & $4.639 \mathrm{E}+275$ \\
\hline & [Twitter] & -10.775 & 8419.614 & .000 & 1 & .999 & $2.092 E-5$ & .000 &.${ }^{b}$ \\
\hline & [Web Services] & -10.597 & 212.322 & .002 & 1 & .960 & $2.498 E-5$ & 4.662E-186 & $1.339 \mathrm{E}+176$ \\
\hline & [Both] & .703 & 1.565 & .202 & 1 & .653 & 2.020 & .094 & 43.395 \\
\hline & [OTC] & 1.329 & 1.606 & .685 & 1 & .408 & 3.776 & .162 & 87.841 \\
\hline & [Prescription] & $0^{c}$ & . & $x^{\circ}$ & 0 & . & . & . & . \\
\hline \multirow{9}{*}{$\begin{array}{c}\text { Above } \\
\text { Average } \\
(7-8)\end{array}$} & Intercept & 11.323 & 212.328 & .003 & 1 & .957 & & & \\
\hline & [Digital App] & -9.989 & 212.325 & .002 & 1 & .962 & $4.590 \mathrm{E}-5$ & 8.527E-186 & $2.471 \mathrm{E}+176$ \\
\hline & [Facebook] & -26.959 & 1652.427 & .000 & 1 & .987 & $1.958 \mathrm{E}-12$ & .000 & ${ }^{b}$ \\
\hline & [Instagram] & -11.002 & 429.474 & .001 & 1 & .980 & $1.666 \mathrm{E}-5$ & .000 &. \\
\hline & [Twitter] & -10.834 & .000 & . & 1 & . & $1.972 \mathrm{E}-5$ & $1.972 \mathrm{E}-5$ & $1.972 \mathrm{E}-5$ \\
\hline & [Web Services] & -11.792 & 212.326 & .003 & 1 & .956 & 7.562E-6 & 1.400E-186 & $4.085 E+175$ \\
\hline & [Both] & -.712 & 1.649 & .186 & 1 & .666 & .491 & .019 & 12.431 \\
\hline & [OTC] & -.669 & 1.777 & .142 & 1 & .706 & .512 & .016 & 16.651 \\
\hline & [Prescription] & $0^{c}$ & . & . & 0 & . & . & . & . \\
\hline
\end{tabular}

a. The reference category is: Maximum (9-10)

b. Floating-point overflow occurred while computing this statistic. Its value is therefore set to system missing.

c. This parameter is set to zero because it is redundant. 


\begin{tabular}{|c|c|c|c|c|c|c|c|}
\hline \multicolumn{8}{|c|}{ Tests of Between-Subjects Effects } \\
\hline Source & Dependent Variable & $\begin{array}{l}\text { Type III Sum } \\
\text { of Squares }\end{array}$ & df & Mean Square & $\mathbf{F}$ & Sig. & $\begin{array}{l}\text { Partial Eta } \\
\text { Squared }\end{array}$ \\
\hline \multirow{3}{*}{ Corrected Model } & Medicine Buying & $39.015^{a}$ & 5 & 7.803 & 1.888 & .098 & .046 \\
\hline & Concern on Delivery time & $31.675^{b}$ & 5 & 6.335 & 1.455 & .206 & .036 \\
\hline & Concern on Delivery charges & $42.321^{c}$ & 5 & 8.464 & 1.616 & .158 & .040 \\
\hline \multirow{3}{*}{ Intercept } & Medicine Buying & 816.007 & 1 & 816.007 & 197.473 & .000 & .502 \\
\hline & Concern on Delivery time & 488.988 & 1 & 488.988 & 112.319 & .000 & .364 \\
\hline & Concern on Delivery charges & 861.603 & 1 & 861.603 & 164.471 & .000 & .456 \\
\hline \multirow{3}{*}{ Online platform } & Medicine Buying & 39.015 & 5 & 7.803 & 1.888 & .048 & .046 \\
\hline & Concern on Delivery time & 31.675 & 5 & 6.335 & 1.455 & .206 & .036 \\
\hline & Concern on Delivery charges & 42.321 & 5 & 8.464 & 1.616 & .158 & .040 \\
\hline \multirow{3}{*}{ Error } & Medicine Buying & 809.921 & 196 & 4.132 & & & \\
\hline & Concern on Delivery time & 853.300 & 196 & 4.354 & & & \\
\hline & Concern on Delivery charges & 1026.773 & 196 & 5.239 & & & \\
\hline \multirow{3}{*}{ Total } & Medicine Buying & 5555.000 & 202 & & & & \\
\hline & Concern on Delivery time & 5495.000 & 202 & & & & \\
\hline & Concern on Delivery charges & 6663.000 & 202 & & & & \\
\hline \multirow{3}{*}{ Corrected Total } & Medicine Buying & 848.936 & 201 & & & & \\
\hline & Concern on Delivery time & 884.975 & 201 & & & & \\
\hline & Concern on Delivery charges & 1069.094 & 201 & & & & \\
\hline
\end{tabular}

a. $\mathrm{R} \mathrm{Squared}=.046$ (Adjusted R Squared $=.022) ;$ b. R Squared $=.036$ (Adjusted R Squared $=.011) ;$ c. R Squared $=.040$ (Adjusted R Squared $=.015)$

revealed by a one -sample t-test that is only using OTC because it offers minimum legal issues and has the potential to be easily integrated into E-Care plans. A focus on standardized integration of OTC information for new and changing products could potentially increase the appropriate choice and use of OTC products for some individuals, allowing the basis by which they can be integrated into pharmacists' patient care process and team-based care. ${ }^{16,17}$

In the response ofto $3^{\text {rd }}$ question website services are significantly adopted by pharmacies to offer their services. Since the web services are considered trustworthy and more informational that offer a far more direct line of communication between pharmacies and consumers. $\left.{ }^{[18}\right]$. In the response ofto the $4^{\text {th }}$ question, pharmacies revealed that multiple online social media platforms are adopted to advertise the products and services, however, more than $50 \%$ selected Instagram followed by Facebook as an advertising online platform. Instagram is the $3^{\text {rd }}$ most powerful social media platform with $>1$ billion monthly active members, since it has become a popular and advanced tool to connect with various types of audiences, particularly younger and female gender. ${ }^{[19\}}$. Pharmacies were also acquired to reveal the digital social media used frequently for communication with the customer. Out of 56 pharmacies, 22(40\%) frequently use WhatsApp as a communication tool with customers followed by web chats $21(38 \%)$. The significant association $(p<0.05)$ of WhatsApp with communication between consumers and businesses may be due to its high ubiquitous adoption rate $(73 \%)$ in Saudi Arabia population and inexpensive way to connect with others. ${ }^{[20]}$ Todays, with a high amount of competition in the pharmacy landscape, pharmacies always look forward to providing the best possible online platforms to engage all the stakeholders. In the present study, $66.7 \%$ of pharmacies prefer to conduct online webinars to engage all stakeholders. Since, webinars can engage diverse stakeholders easily just in one link and this 
engagement is essential in optimizing and implementing the target plans. ${ }^{[21]}$.

The pharmacies that are determined to push their boundaries beyond city walls are more willing to opt for a complete digitalization process. Though the patient safety risks associated with illicit online pharmacies are arguably the most pressing societal concerns, cybersecurity, and privacy issues are also important factors to assess in regards to consumer protection. ${ }^{18}$ The results of the study show similarity in this context and it leads to a conclusion that government needs to provide guidelines and SOP's to pave the path for a more secure and compact digital transformation. E-Health Governance systems can develop dynamically to eradicate global patient safety concerns, ${ }^{19}$ raise awareness among general people and increase the level of trust in major stakeholders. The government plays an important in every field of life especially in this case, where the marketplace for illicit online pharmacies has recently expanded, the risk factors expose patients worldwide to significant safety and security threats. ${ }^{18}$ Social media is an influential digital tool. It offers an association between users (also known as consumers) and is a digital social interactive mechanism for a range of individuals employed in the pharmaceutical industry. ${ }^{20}$ Angela Olkhovska ${ }^{21}$ revealed that the choice of Social Media channels enables pharmaceutical brands to increase customer loyalty, to establish effective feedback from Internet users and improve their service policy, to stand out among competitors, to analyze the popularity of certain posts considering this information in future work to increase sales.

Likewise, in the general set, we also recorded the response ofto 17 questions from consumers actively using pharmacological services. In our first question, we observed a significant difference $(p>0.05)$ with the $70 \%$ of males and $29 \%$ of females (3:1) by applying a one -sample binomial test. Likewise, one-sample binomial test results regarding $2^{\text {nd }}$ and $3^{\text {rd }}$ questions showed $p>$ 0.05 which rejected the null hypothesis and revealed a non-significant difference $(p>0.05)$ difference observed in the proportions of employment status and active subscriber to any pharmaceutical company in customers. We also observed the association of different variables with the frequency of buying medicine online by respondents using multinomial logistic regression and cross -tabulation. The findings of logistic regression showed no significant $(p>0.05)$ association of medicine buying scales (minimum to maximum) with the type of medicine (OTC, Prescription, or both) and online digital platforms (web services, digital app, WhatsApp,
Instagram, Facebook, and t'Twitter) used by customers. It means that the type of medicine and online digital platforms do not impact the medicine buying frequencies significantly (Table 1). Multivariate analysis revealed the effect of online platforms used for medicine buying by customers on medicine buy counts, concerns on delivery time, and charges. Only the medicine buying frequency was significantly eaffected by online platform while, concerns on delivery time and charges did not perceive any significant impact by online platforms.

The advertisement campaigns on social media provide innovative opportunities to incorporate public health alerts and communications with daily online conversations and activities on social media platforms. ${ }^{22}$ The results of the present study indicate that advertisements influence the choices of the customers, therefore, the pharmacies need to be more creative and should use multiple platforms to influence the maximum audience. Emily ${ }^{23}$ reported that the planning and creating of social media content should take into account what will be most engaging, relevant and useful to the target audience, and performing a social media audit is one way of systematically measuring and monitoring performance regularly.

There should be harmony and trust between the service provider and the customer and the numbers show that there are still trust issues and that is not good for digital marketing. In the gradually increasing digital pharmacy communities, where the regional pharmacies must compete with national and global pharmacies the trust between brand personality and customer trust is an important bridge for customer market share. ${ }^{24}$ The department of quality assurance and the feedback needs to be updated to resolve issues between the parties. Digital applications and web services need to be designed carefully so that customers can access things easily and in a very precise manner. There is still huge room to improve in the customer relations department, retention of the customer is based on the performance of this department. Therefore, pharmacies need to train customer service relation agents so they can provide the best services to customers. The numbers also indicate that many people are not satisfied with the current setup of delivery time and charges. The pharmacies need to investigate this and come up with a strategy that works for both parties involved in the transaction. The reaction of the participants also specified that social platforms including Facebook, Instagram and YouTube are playing an effective role in digital marketing of the pharmacies, while the WhatsApp and Messenger groups are commonly used for communication purposes. The 
integration of digital mediums in the pharmaceutical business model not only helped in expanding the range of the pharmacies but also played a vital role in maintaining the financial books during the COVID-19 pandemic and elevated the mutual trust between the customers and the pharmacies. Webinars is the digital technology that holds the potential to engage multiple stakeholders at a time, effects are multidimensional and touch the factor of awareness within the general public, increases the trust process and provide a platform for the physicians to come into this spectrum of E-Pharmacies. Digital media facilitates access to end-users and physicians in an economical way. ${ }^{1}$ The use of e-Care plans in the Saudi Pharmacies can also help them to grow digital subscribers and maintain a fruitful connection with the customers and gain their trust, it will ensure value-based care. The implementation of e-Care plans helped pharmacies in the USA to produce rewarding results. Pharmaceutical companies need a complete reformation in the hiring process and need to employ technical PCR's who are completely familiar with digital devices. Internet marketing activities enables you to obtain the pharmacy a competitive advantage that cannot be evaluated by traditional methods. ${ }^{9}$ The Pharmaceutical Companies need to start their Channels on Digital Platforms so that more people get to know about E-Pharmacies. They need to collaborate and conduct further studies in this department to improve their digital structure and the launch of mobile applications can help every stakeholder involved in the digitalization of the pharmacies. The pharmacies can introduce a platform where a patient can be diagnosed by the physician online, technology has evolved so much and can be incorporated to facilitate this interaction and after the interaction, the pharmacy can provide the services the patient needs. Traditional pharmaceutical is gradually being replaced by digital marketing because it is less time-consuming and favoring easy interactions with customers. ${ }^{25}$

\section{CONCLUSION}

The basic structure of marketing is changing and a digital revolution is knocking at its door. Most marketing campaigns nowadays are running on digital mediums. It is a great opportunity for pharmaceutical companies across the Kingdom of Saudi Arabia to adopt digital platforms for marketing. The people of Saudi Arabia are acquiring modern marketing methods; Saudi customers are looking for platforms to buy medicine and medical services online. This is the digital era; any industry that does not adopt digital marketing methods has the danger of becoming obsolete. Digital media marketing provides greater customer reach for the reduced cost of marketing. There is great potential for marketers and customers alike for availing of digital marketing methods for an essential item such as medicine. The COVID-19 pandemic has shown the pharmaceutical corporates of the world that it is essential that medicine should reach consumers under all circumstances. This is important research that will help both the wellestablished pharmacies and the emerging pharmacies to conduct honest, trustful, and financially viable business. The market behavior differs in every country due to several factors that include the literacy rate, economic and political conditions, infrastructural development, technological advancement, and general awareness among the public. The research includes a study that is conducted in the Middle Eastern Market. The other limitation involves the lack of personalization and the margin of error arising due to the potential dishonest answers in response to the questionnaire. Digitalization is taking all over the globe and with the introduction of artificial intelligence, soon the world will be a different place. This research can help pharmacies to cope up with ever-changing technology and lays down a foundation for further research in the field.

\section{Author Contributions}

Conceptualization, M.A and N.S; Data curation, S.D and S.H; Formal analysis, S.D, S.H and N.S; Funding acquisition, M.A and N.S; Investigation, M.A, S.D, S.H and N.S; Methodology, M.A, S.D, S.H and N.S; Project administration, M.A and S.D; Resources, M.A, S.D, S.H and N.S; Software, S.D and S.H; Supervision, S.D and N.S; Validation, M.A, S.D, S.H and N.S; Writing original draft, M.A, S.D, S.H and N.S; Writing - review and editing, M.A, S.D, S.H and N.S..

\section{Funding}

Funding: The authors extend their appreciation to the Deputyship for Research and Innovation, Ministry of Education in Saudi Arabia for funding this research work through the project number IFT20088

\section{ACKNOWLEDGEMENT}

The authors thank Deanship of Scientific Research, King Faisal University, Al-Ahsa, Saudi Arabia, for their support.

\section{CONFLICT OF INTEREST}

The authors declare no conflict of interest. 


\section{ABBREVIATIONS}

CME: Continuing Medical Education; SOP: Standard operating procedure; USD: United State Dollar; SR: Saudi Riyals; MOH: Ministry of Health.

\section{REFERENCES}

1. Chiplunkar S, Gowda D, Shivakumar H. Adaptation of pharmaceutical marketing and drug promotion practices in times of pandemic COVID-19. IJRHAS. 2020;9(5):11-7.

2. Alkhenizan A. The pharmacoeconomic picture in Saudi Arabia. Expert Rev Pharmacoeconomics Outcomes Res. 2014;14(4):483-90.

3. Al-Jazairi AS, Al-Qadheeb NS, Ajlan A. Pharmacoeconomic analysis in Saud Arabia: An overdue agenda item for action. Ann Saudi Med. 2011;31(4):33541.

4. Radu S. The American newsroom in the new era: Factors that influence the adoption or rejection of new technologies by non-management newspaper news producers. Doctoral dissertation, University of Missouri, Columbia. 2017.

5. Radu G, Solomon M, Gheorghe C, Hostiuc M, Bulescu I, Purcarea V. The adaptation of health care marketing to the digital era. Journal of Medicine and Life. 2017;10(1):44.

6. Walley T. Pharmacoeconomics. In Getting Health Economics into Practice, CRC Press. 2018;137-46.

7. Parsons $\mathrm{A}$, Zeisser $\mathrm{M}$, Waitman R. Organizing today for the digital marketing of tomorrow. J Interact Mark. 1998;12(1):31-46.

8. Jawaid M, Ahmed SJ. Pharmaceutical digital marketing and its impact on healthcare physicians of pakistan: A national survey. Cureus. 2018;10(6).

9. Pestun IV, Mnushko ZM. Effectiveness of current multi-channel marketing in pharmacy. Management, Economy and Quality Assurance in Pharmacy. 2016;1(45):62-6.

10. Paquette H. Social media as a marketing tool: A Literature Review. 2013.

11. Parekh D, Kapupara P, Shah K. Digital pharmaceutical marketing: A review. Research Journal of Pharmacy and Technology. 2016;9(1):108-12.

12. Sarringhaus MM. The great divide: Social media's role in bridging healthcare's generational shift. Journal of Healthcare Management. 2011;56(4):235-44.
13. Zavell AE, Greenberg JN, Alam M, Armbrecht ES, Maher IA. A 30-Minute, Monthly, Live, Webinar-Based Journal Club Activity Alters the Self-reported Behaviors of Dermatologic Surgeons. Dermatol Surg. 2017;43(9):1144-7.

14. Singh H, Majumdar A, Malviya N. E-Pharmacy Impacts on Society and Pharma Sector in Economical Pandemic Situation: A Review. Journal of Drug Delivery and Therapeutics. 2020;10(3-s):335-40.

15. Wright KB. Researching Internet-based populations: Advantages and disadvantages of online survey research, online questionnaire authoring software packages and web survey services. Journal of Computer-mediated Communication. 2005;10(3):1034.

16. Kebodeaux CD. Prescription and over-the-counter medication record integration: A holistic patient-centered approach. Journal of the American Pharmacists Association. 2019;59(2):S13-7.

17. Kebodeaux, Clark D. Prescription and over-the-counter medication record integration: A holistic patient-centered approach. J Am Pharm Assoc. 2019; 59(2): S13-S17.

18. Mackey TK, Nayyar G. Digital danger: A review of the global public health, patient safety and cybersecurity threats posed by illicit online pharmacies. $\mathrm{Br}$ Med Bull. 2016;118(1): 110-26.

19. Mackey TK, Liang BA. Pharmaceutical digital marketing and governance: Illicit actors and challenges to global patient safety and public health. Glob Health. 2013;9(1):45.

20. Moorhead SA, Hazlett DE, Harrison L, Carroll JK, Irwin A, Hoving C. A new dimension of health care: Systematic review of the uses, benefits and limitations of social media for health communication. Journal of Medical Internet Research. 2013;15(4):e85.

21. Olkhovska A, Ab OJTPIJ. Marketing communication and digital technology innovative instruments in promoting pharmaceutical brands in Ukraine and their efficiency estimation. Pharma Innovation. 2016;5(9, part A):38-43.

22. Gupta A, Tyagi M, Sharma D. Use of social media marketing in healthcare. Journal of Health Management. 2013;15(2):293-302.

23. Chen E, DiVall M. Social Media as an Engagement Tool for Schools and Colleges of Pharmacy. Am J Pharm Educ. 2018;82(4):6562.

24. Perepelkin J, DiZhang D. Brand personality and customer trust in community pharmacies. International Journal of Pharmaceutical and Healthcare Marketing. 2011.

25. Ben SY, Bragazzi NL, Pyatigorskaya NV. Prevalence and Perceived Effectiveness of Pharmaceutical Digital Marketing among Community Pharmacies in Saudi Arabia: A Cross-sectional Questionnaire-based Survey. Pharmacy. 2020;8(1):9
PICTORIAL ABSTRACT

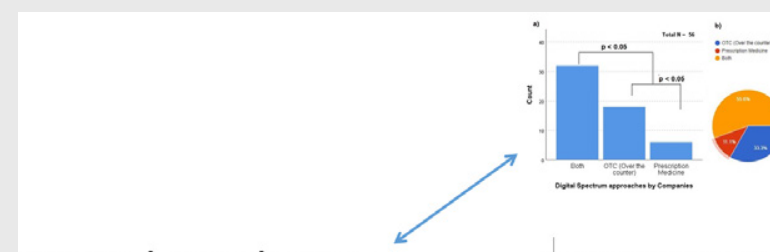

Digital Marketing
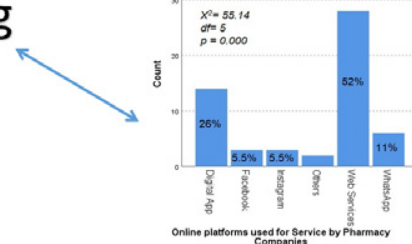

\section{SUMMARY}

The COVID-19 pandemic has shown the pharmaceutical corporates of the world that it is essential that medicine should reach consumers under all circumstances. This is important research that will help both the wellestablished pharmacies and the emerging pharmacies to conduct honest, trustful, and financially viable business

\section{About Authors}

Dr Mansour AlYahya is an Assistant Professor in Marketing at King Faisal University and is interested in digital marketing and the use of technology in tourism. $\mathrm{He}$ is also an active researcher in the field of consumer confusion.

Cite this article: Alyahya M, Dhruvakumar S, Siddegowda SH, Sreeharsha N. Impacts of Digital Marketing on the Pharmacies Community in Saudi Arabia and Determining the Future Model of the Industry: A Cross-Sectional Questionnaire-based Study. Indian J of Pharmaceutical Education and Research. 2020;54(4):1193-206. 